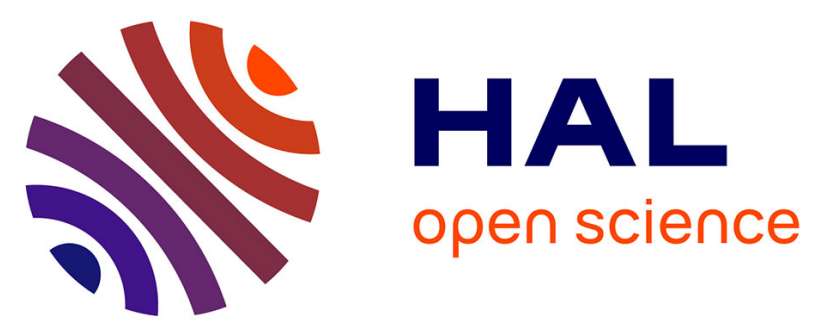

\title{
Organization Science improves management effectiveness of Marine Protected Areas
}

\author{
Claudia Scianna, Federico Niccolini, Sylvaine Giakoumi, Antonio Di Franco, \\ Steven D. Gaines, Carlo Nike Bianchi, Luisa Scaccia, Simone Bava, Valentina \\ Cappanera, Eric Charbonnel, et al.
}

\section{To cite this version:}

Claudia Scianna, Federico Niccolini, Sylvaine Giakoumi, Antonio Di Franco, Steven D. Gaines, et al.. Organization Science improves management effectiveness of Marine Protected Areas. Journal of Environmental Management, 2019, 240, pp.285 - 292. 10.1016/j.jenvman.2019.03.052 . hal-03484792

\section{HAL Id: hal-03484792 https://hal.science/hal-03484792}

Submitted on 20 Dec 2021

HAL is a multi-disciplinary open access archive for the deposit and dissemination of scientific research documents, whether they are published or not. The documents may come from teaching and research institutions in France or abroad, or from public or private research centers.
L'archive ouverte pluridisciplinaire HAL, est destinée au dépôt et à la diffusion de documents scientifiques de niveau recherche, publiés ou non, émanant des établissements d'enseignement et de recherche français ou étrangers, des laboratoires publics ou privés.

\section{(ㄷ)(1) $\$$}

Distributed under a Creative Commons Attribution - NonCommerciall 4.0 International 
Version of Record: https:/www.sciencedirect.com/science/article/pii/S030147971930355X

Manuscript_2424ece3191756fafc78cd18e88cd711

\title{
Organization Science improves management effectiveness of Marine Protected Areas
}

\author{
Claudia Scianna $^{\mathrm{a} * \S}$, Federico Niccolini ${ }^{\mathrm{b}}$, Sylvaine Giakoumi ${ }^{\mathrm{a}, \mathrm{c}}$, Antonio Di Franco ${ }^{\mathrm{a}}$, Steven D. Gaines ${ }^{\mathrm{d}}$, Carlo Nike \\ Bianchi $^{\mathrm{e}}$, Luisa Scaccia ${ }^{\mathrm{f}}$, Simone Bava ${ }^{\mathrm{g}}$, Valentina Cappanera ${ }^{\mathrm{h}}$, Eric Charbonnel ${ }^{\mathrm{i}}$, Jean-Michel Culiolij, Giuseppe Di \\ Carlo $^{k}$, Francesco De Franco ${ }^{1}$, Charalampos Dimitriadis ${ }^{m}$, Pier Panzalis ${ }^{n}$, Pasquale Santoro ${ }^{\circ}$, Paolo Guidetti ${ }^{\mathrm{a}, \mathrm{p}}$
}

${ }^{a}$ Université Côte d'Azur, CNRS, UMR 7035 ECOSEAS, Parc Valrose 28, Avenue Valrose, 06108 Nice, France

${ }^{\mathrm{b}}$ Department of Economics and Management, University of Pisa, via C. Ridolfi 10, 56124 Pisa, Italy

${ }^{c}$ ARC Centre of Excellence for Environmental Decisions, School of Biological Sciences, The University of Queensland, Brisbane, Queensland, Australia

${ }^{\mathrm{d} B r e n}$ School of Environmental Science \& Management, University of California, Santa Barbara, CA 93106, USA

e Department of Earth, Environment and Life Sciences, University of Genoa, Corso Europa 26, 16132 Genoa, Italy

${ }^{\mathrm{f}}$ Department of Economics and Law, University of Macerata, Via Crescimbeni 20, 62100 Macerata, Italy

g Marine Protected Area of Isola di Bergeggi, Via A. de Mari 28/D, 17028 Bergeggi, Italy

${ }^{\text {h }}$ Marine Protected Area of Portofino, V. le Rainusso, 1-16038 S. Margherita Ligure, Italy

${ }^{\text {i } M a r i n e ~ P a r k ~ o f ~ C o ̂ t e ~ B l e u e, ~ O b s e r v a t o i r e ~ P M C B-p l a g e ~ d u ~ R o u e t, ~} 31$ Avenue Jean Bart, B.P 42, 13620 Carry-le-Rouet, France

${ }^{\mathrm{j}}$ Office of the environment of Corsica, Natural Reserve of Bouches de Bonifacio, 20250 Corte, France

${ }^{k}$ World Wide Fund for Nature (WWF), Via Po 25/C, 00198, Rome, Italy.

${ }^{1}$ Marine Protected Area of Torre Guaceto, Via Sant'Anna 6, 72012 Carovigno, Italy

${ }^{\mathrm{m}}$ National marine park of Zakynthos, 1 Eleftheriou Venizelou str, Z.C, 29100 Zakynthos, Greece

${ }^{\mathrm{n}}$ Marine Protected Area of Tavolara-Punta Coda Cavallo, via Dante 1, 07026 Olbia, Italy

${ }^{\text {o }}$ Marine Protected Area of Isole Tremiti, Via Sant'Antonio Abate 121, 71037 Monte Sant'Angelo, Italy

p Interuniversity Consortium of Marine Sciences (CoNISMa), Piazzale Flaminio 9, 00196 Rome, Italy

*Corresponding author: Laboratoire ECOMERS, CNRS FRE 3729, Université Nice Sophia Antipolis, Parc Valrose, 28 Avenue Valrose, 06108 Nice Cedex 2, FRANCE. Tel: +33492076833. Fax: +33492076849. Email address: claudiascianna@gmail.com

$\S$ Present address: World Wide Fund for Nature (WWF), Via Po 25/C, 00198, Rome, Italy 


\begin{abstract}
The ecological management effectiveness (EME) of Marine Protected Areas (MPAs) is the degree to which MPAs reach their ecological goals. The significant variability of EME among 4 MPAs has been partly explained by MPA design, management and implementation features (e.g. surface area, enforcement, age of protection). We investigated EME variability by employing, for the first time, Organization Science. Eight Mediterranean MPAs were taken into account as case studies to explore the relationships between EME and MPA features, such as: 1) organizational size (i.e. the ratio between the number of full-time employees and the total MPA surface area), 2) management performance (i.e. the level of effort exerted to enhance and sustain the MPA management, including enforcement), 3) total surface area, and 4) MPA age. The log-response ratios of fish biomass and density in protected $v s$ unprotected (control) areas were used as a proxy of EME. Management performance, organizational size and, to a lesser extent, MPA age were positively correlated with the log-response ratio of fish biomass, whereas total surface area did not display a significant role. None of the four features considered was significantly correlated with the log-response ratio of fish density. Based on our findings, we argue that the employment of Organization Science in the management effectiveness assessment can assist MPA managers to reach MPAs goals more effectively, with a more efficient use of available resources.
\end{abstract}

\title{
Keywords
}

Marine conservation, management performance, employees, fish biomass, management process 


\section{Introduction}

Marine Protected Areas (MPAs) are broadly considered as effective tools to achieve ecological - biodiversity conservation, restoration of overexploited populations and communities/ecosystems -, cultural - preservation of traditional human activities -, recreational - tourism, boating- and/or socio-economic - improvement of local livelihood, creation of job opportunities, fishery enhancement- goals (Gaines et al., 2010; Day, 2012; Sala et al., 2013). The degree to which MPAs reach their goals is defined as 'management effectiveness' (Hockings et al., 2006).

The ecological management effectiveness (EME) of MPAs refers to the achievement of ecological goals, and is the most frequently assessed aspect of MPA management effectiveness (McClanahan et al., 2006; Gill et al., 2017). It is usually assessed by comparing one or more biological descriptors -e.g. density, size and biomass of species, species richness- or assemblages' patterns inside and outside protected areas (Lester et al., 2009; Guidetti et al., 2014; Giakoumi et al., 2017). Many MPA ecological goals are linked to the restoration of depleted fish stocks, as fishing is one of the most common extractive activities in the ocean (Lubchenco et al., 2003; Worm et al., 2009). Target fish species and assemblages are thus more likely to respond to the protection measures adopted and enforced inside MPAs, especially in the fully protected i.e. no-take- areas (Micheli et al., 2004; Guidetti et al., 2008; Sala and Giakoumi, 2017). Most studies assessing EME, therefore, have focused on fish assemblages.

EME is highly variable among MPAs in space and time (Edgar et al., 2014; Pendleton et al., 2017), and this variability has been attributed to a number of MPA features mainly related to MPA design and implementation, such as total MPA surface area, fully protected surface area, level of geographical isolation, level of protection -i.e. fully/partially protected areas-, age -time since protection-, and level of enforcement (Claudet et al., 2008; Guidetti et al., 2008; Edgar et al., 2014; Di Franco et al., 2018). Yet, these MPA design and implementation features explain only part of the EME variability (Lester et al., 2009; Giakoumi et al., 2017). To further explain this variability, some studies have considered some management aspects of MPAs as features that can potentially affect their management effectiveness (Rodríguez-Rodríguez et al., 2016; Di Franco et al., 2016; Gill et al., 2017; Worm, 2017). For instance, Gill et al. (2017) showed that inadequate staff capacity can 
compromise the EME of MPAs. Rodríguez-Rodríguez et al. (2016) reported that a better management performance -defined as "the level of effort exerted to enhance and sustain the management of MPAs" by Horigue et al., 2014- can enhance EME. In such a context, the need to apply an interdisciplinary approach to study the management effectiveness of MPAs (including EME) has recently been highlighted in the scientific literature (Fox et al., 2012; Pendleton et al., 2017). A step towards this direction is to consider MPAs as "organizations" (Scianna et al., 2015 and definition available in Supplementary material, Text SM.1), an approach that allows exploration of the potential relationships between MPA organizational dimensions -i.e., the design traits characterizing each organization; Daft, 2016-, management performance (Horigue et al., 2014), and the related management effectiveness. Such an approach has the main advantage to be based on a science, the Organization Science (OS), that has been already used for evaluating the management effectiveness of a variety of organizations (Capon et al., 1990; Kaplan, 2001; Chun \& Rainey, 2005) and, thanks to over a century of research, has developed rigorous methods. This discipline has been created to study the structures, strategies and the context of any organization and to understand how the inner variables can make it successful (Daft, 2016; definition also available in Supplementary material, Text SM.1).

The most recent attempts to assess MPA management effectiveness are based on two main frameworks: the framework IUCN-WCPA for management effectiveness evaluation (Hocking et al., 2000) and the framework for the implementation of the IUCN Green List Programme (IUCN-WCPA, 2016). The first framework, on which other studies rely (e.g. Ervin, 2003; Stolton et al., 2007), does not provide any standardized methodology, as stated by the authors. This has led to the possibly to create diverse indicators for the assessment of MPA management effectiveness and to the need by Leverington et al. (2010) to create an overall system of nested indicators. Despite this big effort, some weakness, from the organizational point of view, can be found in such method. For instance, one headline indicator in the "planning" element is "Protected area gazettal". The legal establishment of a protected area should be the minimum requirement to start its assessment because an organization, and as well as any protected area, cannot be effective if it does not exist. "Marking and security or fencing of park boundaries", another headline indicator in the element "planning", is, from an 
organizational point of view, an activity linked to the wider strategy of implementation of the law together with the enforcement (other activity). The planning should overall account for the designing of the strategy and the methods to carry out the relative activities. The second framework employs the social management effectiveness (the achievement of the social goals) as standards for the achievement of the conservation outcomes. It seems that more attention should be paid in the planning and therefore in setting goals, strategy and activities.

The extreme variability in MPAs management effectiveness remains one of the main issues in MPAs science for its consequences on biodiversity and natural resources conservation, and its social impacts on local communities (Lester et al., 2009; Giakoumi et al., 2017). Despite the great efforts made by experts and researchers, the existing frameworks are still not able to fully identify the factors determining such variability. Improving the methodological approaches to assess MPAs' management effectiveness is also pivotal to assess the achievement of international targets to which countries are officially committed (Aichi target 11 of the CBD, 2011; SDG target 14, UNEP, 2015). This is especially true in the marine context where the coverage of protected areas is $5.1 \%$, of the global oceans, very far from the achievement of the targets and way behind the terrestrial sphere where the coverage is $14.8 \%$ of the terrestrial areas (UNEP-WCMC \& IUCN, 2016).

Here, we employed the Organization Science (Daft, 2016) to explore, for the first time, the relationships between the EME of Mediterranean MPAs and their 1) organizational dimensions, 2) management performance, and 3) design and implementation features. To assess the EME of MPAs, general ecological objectives were taken into account using commonly employed descriptors (see Gill et al., 2017) such as the differences between the fish fauna inside the MPAs and in unprotected areas. The results of these analyses can provide guidance on how to improve MPA management by drawing on the insights from effectively run organizations.

\section{Methods}

\subsection{Study area and data collection}

In the present study, we considered eight MPAs located in the north Mediterranean Sea for which both organizational and ecological data were available (Figure 1, Table 1). 
114

115

116

117

118

119

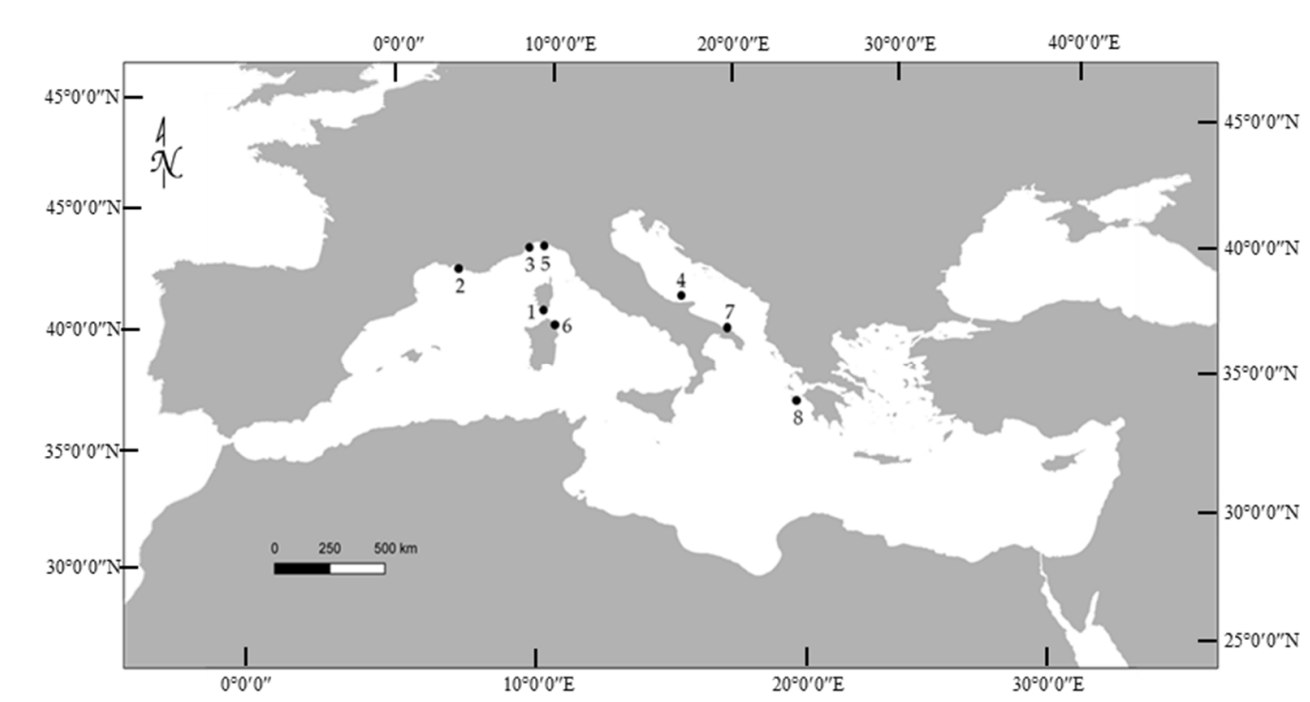

120

121

122

123

124

125

126

\begin{tabular}{lcccc}
\hline \multicolumn{1}{c}{ MPA } & Country & $\begin{array}{c}\text { Total surface } \\
\text { area }\left(\mathbf{K m}^{\mathbf{2}}\right)\end{array}$ & $\begin{array}{c}\text { Fully protected } \\
\text { surface } \mathbf{a r e a}\left(\mathbf{K m}^{\mathbf{2}}\right)\end{array}$ & Age \\
\hline Bouches de Bonifacio Natural Reserve (Bonifacio) & France & 796.40 & 11.30 & 15 \\
Côte Bleue Marine Park (Côte Bleue) & France & 98.73 & 2.95 & 32 \\
Isola di Bergeggi MPA (Bergeggi) & Italy & 2.15 & 0.034 & 7 \\
Isole Tremiti MPA (Tremiti) & Italy & 14.66 & 1.80 & 19 \\
Portofino MPA (Portofino) & Italy & 3.46 & 0.19 & 13 \\
Tavolara - Punta Coda Cavallo MPA (Tavolara) & Italy & 150.00 & 5.35 & 11 \\
Torre Guaceto MPA (Torre Guaceto) & Italy & 22.00 & 1.87 & 14 \\
Zakynthos National Marine Park (Zakynthos) & Greece & 83.31 & 8.01 & 14 \\
\hline
\end{tabular}
MPA management performance and organizational size (Table 2). An extensive data mining effort was carried out to compile only factual and not perceptional data (e.g. expert opinion), in contrast to previous similar studies in which expert judgment was used to fill data gaps (e.g. Pomeroy et al., 2004; Edgar et al., 2014; Gill et al., 2017).

Figure 1. Geographical location of the 8 MPAs investigated (numbered in alphabetical order). 1) Bouches de Bonifacio Natural Reserve (Corsica, France), 2) Côte Bleue Marine Park (France), 3) Isola di Bergeggi MPA (Italy), 4) Isole Tremiti MPA (Italy), 5) Portofino MPA (Italy), 6) Tavolara-Punta Coda Cavallo MPA (Italy), 7) Torre Guaceto MPA (Italy), 8) Zakynthos National Marine Park (Greece).

Table 1. Main features of the 8 MPAs investigated in the present study

Organizational data were gathered from Scianna et al. (2018), in particular the data relative to 
In Scianna et al. (2018), management performance was assessed through the Management Performance Index (MPI), an index specifically created to evaluate the overall effort deployed by the management body to manage the MPA. MPI is composed of two subindices: the culture and goal index (CGI) and the strategy index (SI). These two sub-indices evaluate the overall effort deployed by each management body respectively in: 1) planning for the future both in the long (mission and vision) and the short terms (goals), and 2) planning and carrying out (strategy) the relevant activities to reach goals that are consistent with the longer term mission and vision (see Table 2 for their scores). SI is composed of four sub-components that evaluate the effort for each of the four activities performed inside an MPA (EEI= environmental education index; $\mathrm{EI}=$ enforcement index; $\mathrm{MI}=$ monitoring index; $\mathrm{MDI}=$ management data index). Detailed definitions of the mission, vision, goals and strategy are available in Supplementary material (Text SM.1), and Scianna et al. (2018).

Table 2. Scores of CGI (Culture and Goals Index), SI (Strategy Index), MPI (Management Performance Index) and organizational size. CGI and SI values can range from zero to eight (maximum value, see Scianna et al., 2018 for more details). The MPI is computed through the formula: MPI $=\sqrt{ }\left(\left(\mathrm{CGI}^{2}+\mathrm{SI}^{2}\right) / 2\right)$, so that its maximum score is again 8 .

\begin{tabular}{lcccc}
\hline \multicolumn{1}{c}{ MPA } & CGI & SI & MPI & Organizational size \\
\hline Bouches de Bonifacio Natural Reserve & 3 & 5 & 4.12 & 0.04 \\
Côte Bleue Marine Park & 4.5 & 5.25 & 4.89 & 0.08 \\
Isola di Bergeggi MPA & 4 & 3.75 & 3.88 & 1.76 \\
Isole Tremiti MPA & 4 & 2.75 & 3.43 & 0.12 \\
Portofino MPA & 6.5 & 2 & 4.81 & 2.31 \\
Tavolara - Punta Coda Cavallo MPA & 4.5 & 3.75 & 4.14 & 0.05 \\
Torre Guaceto MPA & 6.5 & 5.25 & 5.91 & 0.77 \\
Zakynthos National Marine Park & 2 & 5.5 & 4.14 & 0.47 \\
\hline
\end{tabular}

Organizational size is defined in Organization Science as the workforce or the funding that the organization can rely upon to carry out its strategy (Daft, 2016). Here, we consider the workforce component of the organizational size, calculated as the ratio between the number of full-time equivalents - the equivalent number of employees working full-time in an organization - and the total MPA surface area in $\mathrm{km}^{2}$. To this end, "MPA organizational size" is used to refer to the workforce of MPAs standardized by the MPA's surface area. In the 


$$
R R=\ln \left(\bar{X}_{T} / \bar{X}_{C}\right)
$$

\subsection{Data treatment}

present study, therefore, we moved away from the use of "MPAs size" commonly adopted in literature to define the MPA surface area (Claudet et al., 2008; Edgar et al., 2014).

A peer-reviewed literature search was performed to find data on the effect of protection on ecological variables in the investigated MPAs (details and selection criteria available in Supplementary material, Text SM.2). No papers - published in scientific journals with impact factors - meeting all of our selection criteria were found. Thus, the search was extended to cover grey literature and unpublished data.

Technical reports on fish assemblage monitoring were available for seven of the eight target MPAs: Bergeggi, Côte Bleue, Portofino, Tavolara, Tremiti, Torre Guaceto and Zakynthos (more detail available in Supplementary material, Table SM.1 and Table 1 for full MPAs' names; methods used to extract data available in Supplementary material, Text SM.3). In the case of Bonifacio MPA, raw and quantative data on fish density and biomass were directly provided by the management body of the MPA as there were no reports available. The final dataset, suitable for analysis, was thus constituted by data on the total biomass and density of fish from the eight MPAs and respective control areas (Figure 1). Species richness and individual fish size were excluded from the analyses, because the requisite data were available for only a few of the target MPAs.

Finally, data about three design and implementation features of the eight MPAs were collected from the available literature, websites and reports (see Table 1 for their values): 1) total surface area in $\mathrm{km}^{2} ; 2$ ) fully protected surface area in $\mathrm{km}^{2} ; 3$ ) age (the number of years between the implementation of the MPAs and 2014, the year of collection of the organizational data and most ecological data).

To evaluate the EME of the eight MPAs, the log-response ratio ( $R R$, Hedges et al., 1999) for fish biomass and density data was estimated as follow: 
where $\bar{X}_{T}$ and $\bar{X}_{C}$ are the mean values of the observations (either for biomass or density) inside and outside the MPA (control site), respectively. The variance $\left(v_{R R}\right)$ associated with the estimated $R R$ was calculated as:

$$
v_{R R}=\frac{S_{T}^{2}}{N_{T} \bar{X}_{T}^{2}}+\frac{S_{C}^{2}}{N_{C} \bar{X}_{C}^{2}}
$$

where $S_{T}$ and $N_{T}$ are, respectively, the standard deviation and the number of observations (either for biomass or density) inside the MPA, while $S_{C}$ and $N_{C}$ are the corresponding values outside the MPA. Significant differences between fish biomass and density inside versus outside each MPA were detected by calculating the corresponding 95\% confidence interval of the $R R$ as follows:

$$
\left[R R-z_{\alpha / 2} \sqrt{v_{R R}} ; R R+z_{\alpha / 2} \sqrt{v_{R R}}\right]
$$

where $z_{\alpha / 2}$ is the $100(1-\alpha / 2) \%$ percentile of the standard normal distribution and $\alpha$ is the confidence level. If $95 \%$ confidence intervals overlap with the zero value, then the calculated $R R$ values are not statistically significant. The sign of the $R R$ values indicate the direction of the effect. Positive $R R$ values indicate levels that are higher in the MPA than in the corresponding unprotected area.

Then, univariate multiple regressions were carried out to test which features (predictors) were significantly related with $R R s$ of both fish density and biomass (Anderson et al., 2008). To this end, the distance-based multivariate analysis for a linear model procedure (DISTLM) was used to analyze univariate data in response to continuous predictor variables. The marginal and the conditional tests were run using Primer V7 with PERMANOVA+ added on software package (Anderson et al., 2008; Clarke \& Gorley, 2015). The marginal test measures the relationship between a response variable and each predictor separately. The conditional test, on the other hand, looks for such relationships by sequentially adding each predictor to the model (Anderson et al., 2008). 
Before performing the analysis, possible collinearity among the predictor organizational, design and implementation features was checked: organizational size, management performance index (MPI), total surface area, fully protected surface area, and age. A statistically significant correlation was detected among total surface area and fully protected surface area (values available in Supplementary material, Table SM.2). As a result, only four MPA organizational, design and implementation features were used as predictors of the EME: 1) organizational size, 2) management performance index (MPI), 3) total surface area, and 4) age of protection. We also tested the possible relationships between EME and each subcomponent of MPI. This analysis sought to disclose any specific effects of the different components of the management process, taken individually, on EME.

Euclidean distance for both organizational and ecological variables was used, and $p$-values were simulated through 9999 permutations of model residuals (Anderson, 2001). In the DISTLM, the forward method was used (to seek the additive effect of the variables) and the adjusted $\mathrm{R}^{2}$ selection criterion, which is not too severe, nor too generous in including the predictor variables in the model.

\section{Results}

Our results revealed that $R R$ values based on total fish biomass and density were significantly higher in the fully protected areas than in the unprotected areas or in the partially protected area of the Tremiti MPA (Figure 2). The lone exception was Bonifacio MPA, where fish density was higher in the control areas than inside the fully protected area. The biomass inside the MPAs was from 2.59 to 12.40 (mean= 5.90) times higher than in unprotected areas. For seven MPAs, the density inside the protected area was from 1.22 to 4.57 (mean= 2.41) times higher than in unprotected areas. Bonifacio was the exception, with density outside the protected area that was 1.15 times higher than inside. 


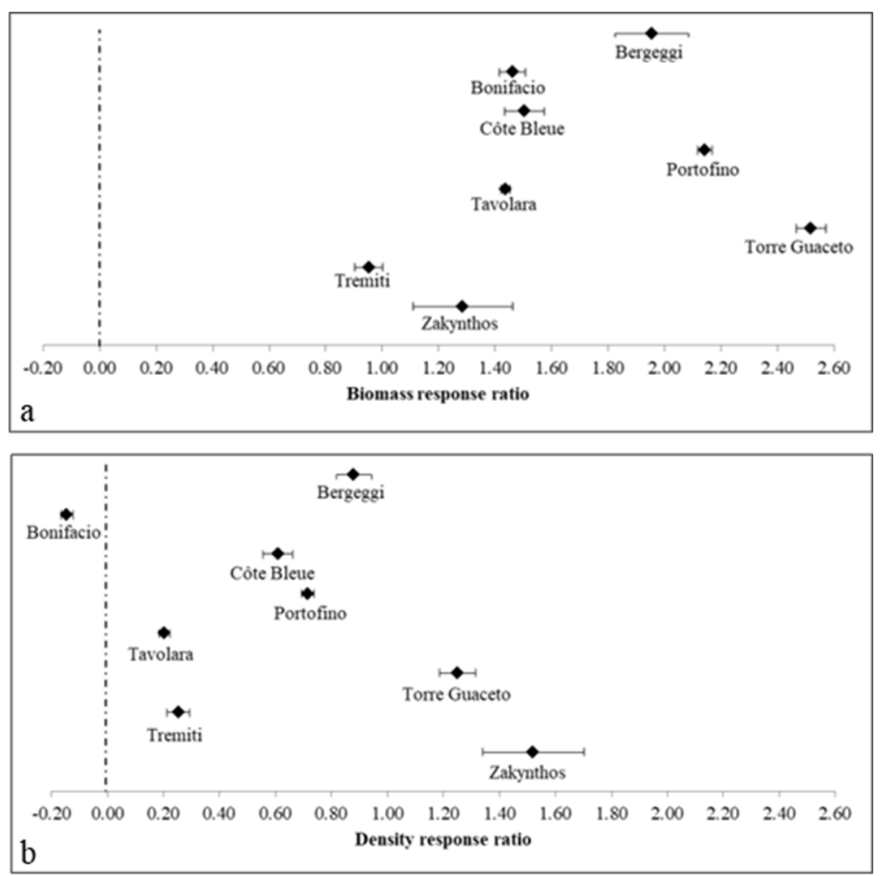

Figure 2. Plots showing the log-response ratios and the corresponding $95 \%$ confidence intervals for total fish biomass (a) and density (b) in eight fully protected areas vs control areas.

As a statistically significant difference between MPAs and control areas was observed, we investigated in depth which predictors better explained the variability in the density and biomass $R R$. Among the four organizational, design and implementation features considered as predictors (i.e. organizational size, MPI, total surface area and age of protection), the MPI, in the marginal test, explained the largest amount of total variability $(\approx 63 \%)$ in fish biomass (Figure 3a; refer to Supplementary material, Table SM.3), showing a correlation coefficient significantly different from zero $(p=0.02)$. The organizational size explained, in the marginal test, $42 \%$ of the variability in fish biomass, and following Gelman (2013), it is weakly significant with a $p$-value close to the threshold of 0.10 (organizational size $p=0.08$; Figure $3 \mathrm{~b}$; refer to Supplementary material, Table SM.3). The remaining two design and implementation features (total surface area and age of protection) did not seem to play any significant individual role in explaining the variability in ecological responses. 

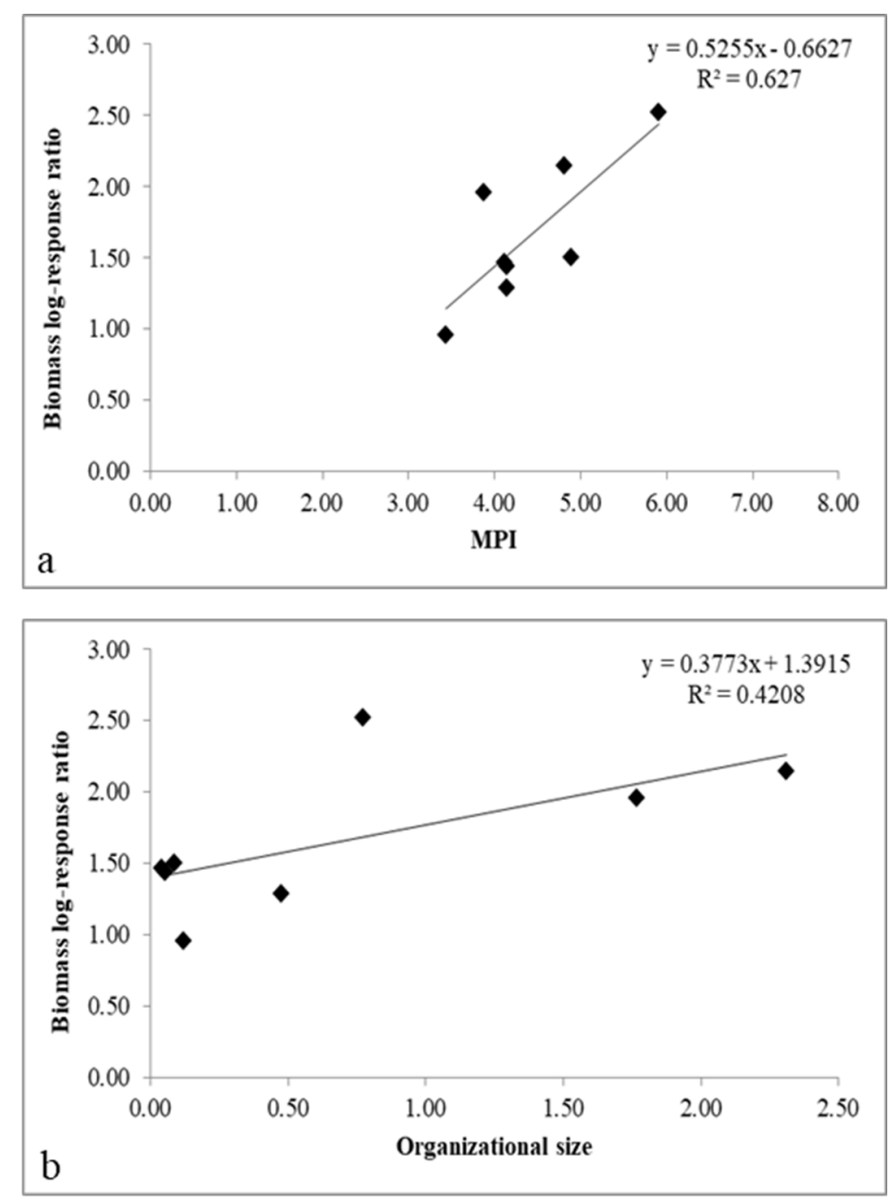

Figure 3. Correlation plots. a: correlation plot between fish biomass log-response ratio and the Management Performance Index (MPI). The scale for MPI ranges from zero to eight by definition (Scianna et al., 2018). b: correlation plot between fish biomass log-response ratio and the organizational size. The values of the organizational size calculated for the eight MPAs range from zero to 2.31 .

When all four predictors were added sequentially to the linear model in the conditional test, based on adjusted $\mathrm{R}^{2}$ selection criterion, the MPI explained $63 \%$ of the total variability ( $p=$ 0.02 ) when considered alone. The second predictor that sequentially increased the adjusted $\mathrm{R}^{2}$ the most, was organizational size $(p=0.03)$. Collectively, these two predictors thus accounted for $88 \%$ of the total variability in the $R R$ based on fish biomass. Age of protection was weakly significant with a $p$ value close to the threshold of 0.10 (age $p=0.09$; Gelman, 2013). Including 
all three predictors explained $94 \%$ of the total variability. Total surface area did not significantly explain any additional variability (refer to Supplementary material, Table SM.3).

Figure 4 shows the joint relationship of the two more significant organizational predictors (MPI and organizational size) with fish biomass $R R$. The two MPAs with the highest biomass RRs (Portofino and Torre Guaceto) were characterized by MPI and organizational size values that were both well above the overall mean values for the MPAs investigated here (MPI mean value $=4.41$; organizational size mean value $=0.70$ ). By contrast, the four MPAs with lower biomass RRs (Bonifacio, Tavolara, Tremiti, and Zakynthos) were characterized by MPI and organizational size that were both below the means. Finally, sites where either MPI or organizational size (but not both) were above the mean had intermediate values of biomass $R R$, as in the case of Bergeggi and Côte Bleue.

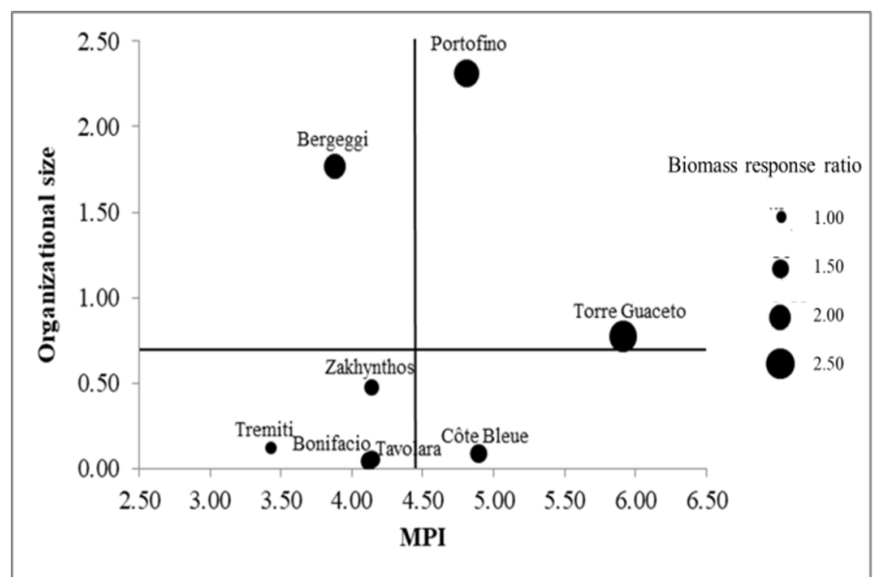

Figure 4. Correlation plot between the organizational size and the MPI (Management Performance Index). The diameter of the bubble is related to the magnitude of the log-response ratio $(R R)$ of fish biomass. The solid lines represent the mean values for both organizational size and MPI calculated for the Marine Protected Areas studied.

Going more in depth on the role of MPI components, marginal test detected that fish biomass $R R$ was significantly and positively related with CGI (culture and goal index, $63 \%$ of the total variability explained, $p=0.00$ ) and with SI (strategy index, $49 \%$ of the total variability explained, $p=0.01$ ) (refer to Supplementary material, Table SM.4). In the conditional test, CGI and SI explained together the $98 \%$ of the total variability ( $p$ for both indices $=0.00$ ). None of the four sub-components of the SI, which evaluate the effort deployed in the main management 
activities, was significantly correlated to biomass $R R$ (refer to Supplementary material, Table SM.5). None of the four predictors considered here was found to have a significant relationship with fish density $R R$.

\section{Discussion}

\subsection{The effect of management performance, organizational size and age of protection on EME}

The findings of this study demonstrate that management performance has a profound influence on the ecological management effectiveness (EME) of the MPAs investigated. Moreover, the strong influence of two MPI subcomponents (the culture and goals index, and the strategy index) on EME of MPAs support the value of deploying greater effort in both planning for the future (mission, vision and goals) and planning and carrying out current activities (strategy) to achieving better MPA effectiveness. The importance of such management aspect is showed also by the presence of planning indicators in other management effectiveness frameworks and assessments (IUCN-WCPA, 2000; Leverignton et al., 2010). On the other hand, the strategic management activities (i.e. enforcement, education, monitoring, and data management/valorization) were not individually strongly linked to EME. This could compromise the effort lavished on one or few of these specific activities if a broader planning is not envisaged and all the essential management activities are carried out simultaneously. Perhaps the most surprising aspect of the little impact from these individual management activities is the lack of any significant effect of enforcement on EME. Enforcement has been considered among the crucial factors driving positive ecological effects inside MPAs (Guidetti et al., 2008; Giakoumi et al., 2017; Gill et al., 2017). One possible source of this discrepancy that warrants further exploration is the qualitative difference in measures of enforcement between this study and previous examples. Most of them evaluated the level of enforcement based on expert opinion (Claudet et al., 2008; Gill et al., 2017), while we quantified the amount of effort deployed in enforcement activities (e.g. the hours spent for the surveillance divided by the MPA total surface area and the methods adopted for the surveillance). Expert opinion estimates of enforcement activity may incorporate components of both enforcement effort and broader management strategies. In addition, the effort deployed in enforcement activities by the 
MPAs considered here was in general quite low with limited variability across locations. This provides limited power in exploring the impacts of enforcement intensity on EME.

The observed impacts of management performance and its subcomponents provide several insights on how to improve MPA management effectiveness and design guidelines for MPAs management and decision makers. The results underline the importance to define vision, mission and quantitative goals, as well as the need of designing a proper strategy.

MPA organizational size, measured here as the total number of full-time employees (the actual workforce that carries on MPA activities throughout the year) weighted by the MPA surface area, is also positively related to EME. This evidence is consistent with the results by Gill et al. (2017), who reported that an adequate staff capacity is the key management factor that explains fish responses to MPAs. Our study is the first, to our knowledge, that standardized human resources employed in an MPA, taking into account the work time and the MPA surface area, rather than looking solely at the total number of employees (Pomeroy et al., 2004; Hockings et al., 2006; Abdulla et al., 2008). Our standardized approach to assess human resources is likely to provide a more realistic picture of MPA workforce and worktime, relatively to the extension of each MPA, as demonstrated by the additional analysis we performed. Repeating the same analysis and considering the total number of employees, no statistically significant relationship has been found with the biomass $R R$ (refer to Supplementary material, Table SM.6). Our standardized approach, therefore, could help decision makers understand the actual needs of each MPA and properly allocate the resources to improve EME.

The predictor "age of protection" was weakly but positively correlated with EME. According to previous studies, such a result is attributable to ecological, social and organizational processes that need time to work, e.g. the time needed for MPA ecological benefits to develop, the time needed for the same ecological benefits to spill-over from MPAs and allow for a social acceptance of the MPAs, the time needed to raise funds to support MPA management after formal MPA creation (Claudet et al., 2008; Edgar et al., 2014; Giakoumi et al., 2017).

Fish density did not show relationships with any of the predictors considered here. Previous studies already recognized that fish density can be affected by processes partially 
independent of protection (e.g., a successful annual recruitment: Harmelin-Vivien et al., 2008). Fish biomass, on the other hand, is commonly the most responsive indicator of the conservation status of fish assemblages, because it inherently integrates both changes in density and size (Sandin et al., 2008; Sandin \& Sala, 2012; Guidetti et al., 2014), where fish size (especially for species targeted by fishing) is one of the best indicator of the effect of protection (Pelletier et al., 2005; Di Franco et al., 2009).

In accordance with previous findings (Côté et al., 2001; Micheli et al., 2004; Di Franco et al., 2016), the surface area was not statistically correlated with MPA EME (at least in terms of fish biomass or density $R R$ ). Previous studies have reported divergent effects of MPA surface area on EME (Edgar et al., 2014; Giakoumi et al., 2017). This variation may reflect the consequences of interactions between the biology of the species being fished (e.g., fish home range, changes in habitat during development) and MPA area, which are not adequately addressed in many studies, our analyses included (see Di Franco et al., 2018 for further discussion).

Finally, a high percentage (94\%) of EME variability was explained by MPI, organizational size and age of protection. This output suggests that applying Organization Science and together considering design and implementation features to assess MPAs effectiveness, is more than promising.

\subsection{Limitations of the present study}

Four shortcomings of the current study may limit the generality of our findings. First, the number of the MPAs studied $(n=8)$ is fairly restricted because of the paucity of settings where both ecological and organizational data are available (Guidetti, 2002; Claudet \& Guidetti, 2010; Ferraro \& Hanauer, 2014). Gill et al. (2017) faced the same problem in their study aimed at investigating the link between MPA management features and their ecological effectiveness on a worldwide scale. Globally, MPA management bodies rarely collect the ecological, organizational and management data that make such analyses possible. Rectifying this data limitation is a key to exploring the generality of the results observed in the Mediterranean and to be able to give more detailed guidelines on the scores of management performance and organizational size needed to reach a high level of management effectiveness. 
Second, the present study focused on fish density and biomass $R R$ to test for correlations with a number of MPAs features related to their organization, design and implementation. We used fish density and biomass, because these were the only comprehensively available data. However, other ecological components are also potentially influenced by protection (Gaines et al., 2010; Guidetti \& Sala, 2007). Moreover, fish density and biomass $R R$ are affected by the conditions both inside and outside MPAs. Within-MPA conditions are usually better quantified than conditions outside, often just described as 'open to fishing' (Claudet \& Guidetti, 2010). When the effectiveness of an MPA is assessed in relation to external controls, the state of control locations outside the protected areas can play a major, but unmeasured, role in the magnitude of responses.

Third, in this study we assessed responses of two ecological variables. Yet, MPAs usually have multiple objectives (e.g., ecological, socio-cultural, economic: Fox et al., 2012), which may also depend on the strategy or trade-offs adopted by each MPA management body (Berger et al., 2016). The MPA overall effectiveness (or success), from this perspective, can be properly evaluated only by considering the achievement of a broader range of objectives. Applying a similar approach with more diverse response variables and a larger number of MPAs across a wider geographical scale would provide a more comprehensive assessment of the key management characteristics that help drive MPA success.

Lastly, we did not provide data on another essential component of the organizational size: funding. Despite the important role that funding can play in the management process (Gill et al., 2017), it was not possible to collect such data for most of the MPAs studied here. Data about funding, in fact, are often considered "sensitive and delicate", and management bodies are commonly not willing to share them.

\subsection{Perspectives}

Our results provide two main hints for the future research on MPAs: a) the opportunity to complement two different disciplines such as MPA science and Organization science for future studies on MPA management effectiveness, so that any changing condition that will occur inside a MPA could be managed relying on the OS scientific and rigorous methods and on the expertise in the management process gathered by organizational scientists over a century 
of research; b) the need to shift from the current methods based on experts judgments (e.g. Pomeroy et al., 2004; Edgar et al., 2014; Gill et al., 2017) to other based on factual and quantitative indices and comparable and empirical data collected in an standardized manner.

In the light of the available literature, our results make it possible also to develop a 413 well-structured and more comprehensive framework to identify the crucial steps for a standardized and adaptive management process of an MPA (Figure 5a). Such framework is based on a new correlation between management performance and management effectiveness considered now as one dependent from the other, and not synonymous as they have been mostly considered so far. Initially, the mission and the vision of an MPA should be formalized to guide goal setting (Nanus, 1992). The goals should account for a wide array of protection effects: ecological, cultural and socio-economic (Watson et al., 2014). To achieve high MPA management effectiveness, goals should be quantitative and refined through time (Ban et al., 2012). Appropriate metrics and data collection protocols should be selected and standardized to track the degree of goals achievement (Parma, 1998). The strategy should be designed consistently with the formalized mission, vision and goals, to provide clarity on crucial activities, like enforcement, environmental education and monitoring (Campbell \& Yeung, 1991). Long-term monitoring using appropriate protocols can assess performance and effectiveness based on the goals set (Guidetti \& Claudet, 2010; Lubchenco \& Grorud-Colvert, 2015; Lamb, 2017). Standard methods for data collection should be defined to make the data readily available and comparable across MPAs (Lester et al., 2009). Collectively, such steps within an adaptive management framework could improve significantly MPA management performance and effectiveness (Grafton \& Kompas, 2005; Ban et al., 2012). 

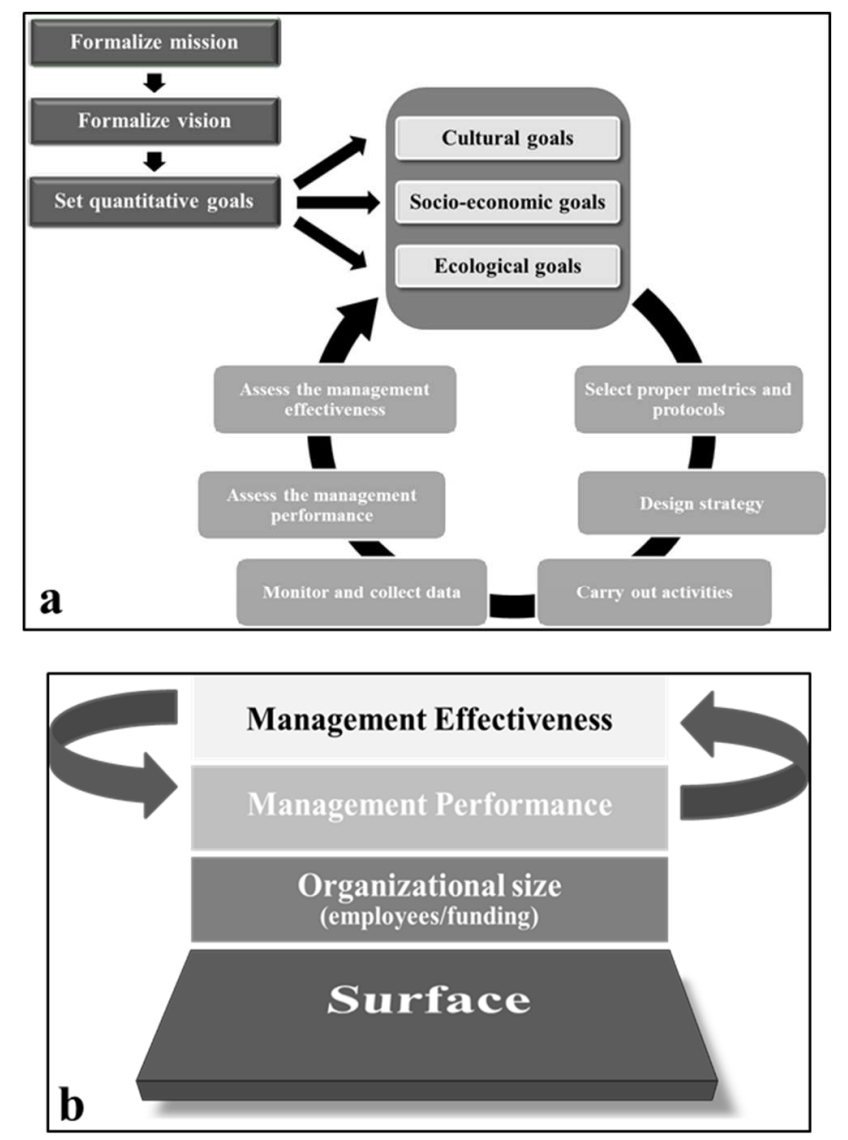

Figure 5. Conceptual models on how to improve the management process. a: framework for the adaptive management process of an MPA. b: critical elements related to and supporting the creation and management of MPAs. Arrows show the dynamic process between the management performance and the management effectiveness. Management performance affects management effectiveness, which, once assessed, can give important hints on the rearrangement of the management performance.

The results of this study, also, give a thought to the sequential links among organizational size related to MPA surface area, management performance and management effectiveness (Figure 5b). Resources, in terms of employees and funding needs, should be planned a priori once an MPA is created, taking into consideration at least its surface area. The employees (manager and staff, based on their number and competences) are the main drivers of the level of management performance which in turn reflects on the management effectiveness of the MPA, as showed by our results. Once the management effectiveness is assessed, MPA management bodies have the critical information on the rearrangements that are needed to 
further improve the management performance which again affects the management effectiveness (see arrows in the figure).

\subsection{Conclusions}

The present study provides quantitative evidence on the relationship between MPA management effectiveness, the effort deployed in the management (performance) and the fulltime workforce standardized by the surface area of the MPA. It also shows the value of assessing these features through the employment of the Organization Science. This approach could help reduce the ambivalence about to what end (mission, vision, goals) and how (strategy and actions) MPAs are used. By improving the methodologies for the assessment of MPA management effectiveness, we could improve our understanding of key drivers and thereby make MPAs more effective. This is particularly important if we consider that the resources available for MPA management are usually scarce and understanding how to reach 'effective' management is fundamental for defining where and how to prioritize resource investments.

\section{Acknowledgements}

We would like to thank, first of all, the MPA managers we have interviewed and who provided us with essential information (in alphabetic order): Frédéric Bachet, Madeleine Cancemi, Alessandro Ciccolella, Paolo D’Ambrosio, Drosos Koutsoubas, Giorgio Fanciulli, Juan Carlos Jorquera Gámez, Silvia Revenga Martínez de Pazos, Augusto Navone, and Laurent Sourbes. We also wish to thank some staff members who kindly provided supplementary data and explanations: Pasquale Baiata, Sergio Fai, Tiziana Ferrando, Javier Llorente Palao, and Luciana Muscogiuri.

\section{Funding}

The present study has been supported by the 'Prince Albert II of Monaco Foundation' (Monaco), the 'Total Corporate Foundation' (France), MedPAN (France), the Agence Française pour la Biodiversité (France), Waitt Foundation, and the WWF-MedPO (Italy). 


\section{References}

476

477

478

479

480

481

482

483

484

485

486

487

488

489

490

491

492

493

494

495

496

497

498

499

500

501

502

503

504

Abdulla, A.G., Maison, M., Piante, C., 2008. Status of marine protected areas in the Mediterranean Sea. UICN, Málaga (España) WWF, París (France). 2831710979.

Anderson, M.J., 2001. Permutation tests for univariate or multivariate analysis of variance and regression. Can J Fish Aquat Sci. 58, 626-639.

Anderson, M.J., Gorley, R.N., Clarke, K.R., 2008. PERMANOVA+ for PRIMER: Guide to Software and Statistical Methods. PRIMER-E: Plymouth, UK.

Ban, N.C., Cinner, J.E., Adams, V.M., Mills, M., Almany, G.R., Ban, S.S., et al., 2002. Recasting shortfalls of marine protected areas as opportunities through adaptive management. Aquat Conserv. 22(2):262-71.

Campbell, A., Yeung, S., 1991. Brief case: mission, vision and strategic intent. LRP. 24(4), 145-147.

Capon, N., Farley, J.U., Hoenig, S., 1990. Determinants of financial performance: a metaanalysis. Manage Sci. 36(10): 1143-1159.

CBD., 2011. Convention on Biological Diversity: The Strategic Plan for Biodiversity 20112020 and the Aichi Biodiversity Targets. Available from: http://www.cbd.int/sp/targets/.

Clarke, K.R., Gorley, R.N., 2015. PRIMER v7: User Manual/Tutorial. PRIMER-E, Plymouth.

Claudet, J., Guidetti, P., 2010. Improving assessments of marine protected areas. Aquat Conserv. 20(2): 239-42. 
Claudet, J., Osenberg, C.W., Benedetti-Cecchi, L., Domenici, P., García-Charton, J.A., PérezRuzafa, Á., et al., 2008. Marine reserves: size and age do matter. Ecol Lett. 11(5):481-9.

Côté, I.M., Mosqueira, I., Reynolds, J.D., 2001. Effects of marine reserve characteristics on the protection of fish populations: a meta-analysis. J Fish Biol. 59: 178-189.

Chun, Y.H., Rainey, H.G., 2005. Goal ambiguity and organizational performance in US federal agencies. J Publ Adm Res Theor. 15(4): 529-557.

Daft, R., 2016. Organization theory and design $12^{\text {th }}$ ed. Cengage Learning.

Day, J., Dudley, N., Hockings, M., Holmes, G., Laffoley, D.d.A., Stolton, S., Wells S.M., 2012. Guidelines for applying the IUCN protected area management categories to marine protected areas. IUCN.

Di Franco, A., Bussotti, S., Navone, A., Panzalis, P., Guidetti P., 2009. Evaluating effects of total and partial restrictions to fishing on Mediterranean rocky-reef fish assemblages. Mar Ecol-Prog Ser. 387: 275-285.

Di Franco, A., Plass-Johnson, J., Di Lorenzo, M., Claudet, J., Gaines, S.D., García-Charton, J.A., Giakoumi, S., Grorud-Colvert, K., Werner Hackradt, C., Micheli, F., Guidetti, P., 2018. Linking home ranges to protected area size: the case study of the Mediterranean Sea. Biol Conserv. 221: 175-181. Doi: 10.1016/j.biocon.2018.03.012

Di Franco, A., Thiriet, P., Di Carlo, G., Dimitriadis, C., Francour, P., et al., 2016. Five key attributes can increase marine protected areas performance for small-scale fisheries management. Sci Rep. 6, 38135; doi: 10.1038/srep38135. 
Edgar, G.J., Stuart-Smith, R.D., Willis, T.J., Kininmonth, S., Baker, S.C., Banks, S., et al., 2014. Global conservation outcomes depend on marine protected areas with five key features. Nature. 506: 216-220.

Ervin, J., 2003. WWF: Rapid Assessment and Prioritization of Protected Area Management (RAPPAM) Methodology. WWF Gland, Switzerland.

Ferraro, P.J., Hanauer, M.M., 2014. Advances in measuring the environmental and social impacts of environmental programs. Annu Rev Env Resour. 39: 495-517.

Fox, H.E., Mascia, M.B., Basurto, X., Costa, A., Glew, L., Heinemann, D., 2012. Reexamining the science of marine protected areas: linking knowledge to action. Conserv Lett. 5(1): 1-10.

Gaines, S.D., Lester, S.E., Grorud-Colvert, K., Costello, C., Pollnac, R., 2010. Evolving science of marine reserves: new developments and emerging research frontiers. PNAS. 107: $18251-18255$.

Gelman, A., 2013. P Values and Statistical Practice. Epidemiology. 24: 69-72.

Giakoumi, S., Scianna, C., Plass-Johnson, J., Micheli, F., Grorud-Colvert, K., Thiriet, P. et al., 2017. Ecological effects of full and partial protection in the crowded Mediterranean Sea: a regional meta-analysis. Sci Rep. 7: 8940. doi:10.1038/s41598-017-08850-w.

Gill, D.A., Mascia, M.B., Ahmadia, G.N., Glew, L., Lester, S.E., Barnes, M., et al., 2017. Capacity shortfalls hinder the performance of marine protected areas globally. Nature. 543: 665-669.

Grafton, R.Q., Kompas, T., 2005. Uncertainty and the active adaptive management of marine reserves. Mar. Policy. 29: 471-479. 
Guidetti, P., Baiata, P., Ballesteros, E., Di Franco, A., Hereu, B., Macpherson, E., et al., 2014. Large-scale assessment of Mediterranean marine protected areas effects on fish assemblages. PloS One. 9: e91841.

Guidetti, P., Claudet, J., 2010. Comanagement practices enhance fisheries in marine protected areas. Conserv Biol. 24(1): 312-318.

Guidetti, P., Milazzo, M., Bussotti, S., Molinari, A., Murenu, M., Pais, A., et al., 2008. Italian marine reserve effectiveness: Does enforcement matter? Biol Conserv. 141: 699-709.

Guidetti, P., Sala, E., 2007. Community-wide effects of marine reserves in the Mediterranean Sea. Mar Ecol Prog Ser. 335: 43-56.

Guidetti, P., 2002. Mediterranean MPAs: the importance of experimental design in detecting the effects of protection measures on fish. Aquat Conserv. 12: 619-634.

Harmelin-Vivien, M., Le Diréach, L., Bayla-Sempere, J., Charbonnel, E., et al., 2008. Gradients of abundance and biomass across reserve boundaries in six Mediterranean marine protected areas: evidence of spillover? Biol Conserv. 141: 1829-1839.

Hedges, L.V., Gurevitch, J., Curtis, P.S., 1999. The meta-analysis of response ratios in experimental ecology. Ecology. 80(4): 1150-1156.

Hockings, M., Stolton, S., Leverington, F., Dudley, N., Courrau, J., 2006. Evaluating effectiveness: a framework for assessing management effectiveness of protected areas. 2nd edition. IUCN, Gland, Switzerland and Cambridge, UK.

Hocking M., Stolton S., Dudley N. 2000. Evaluating Effectiveness: A Framework for Assessing the Management of Protected Areas. IUCN, Gland, Switzerland and Cambridge, UK. $\mathrm{x}+121 \mathrm{pp}$. 
593

594

595

596

597

598

599

600

601

602

603

604

605

606

607

608

609

610

611

612

613

614

615

616

617

618

619

620

621

622

Horigue, V., Aliño, P.M., Pressey, R.L., 2014. Evaluating management performance of marine protected area networks in the Philippines. Ocean. Coast. Manage. 95: 11-25.

IUCN, WCPA., 2016. IUCN Green List of Protected and Conserved Areas: Standard, Version 1.1. Gland, Switzerland: IUCN.

Kaplan, R.S., 2001. Strategic performance measurement and management in non-profit organizations. Nonprofit Manag Lead. 11(3): 353-370.

Lamb, D., 2017. Long-term ecological monitoring and institutional memories. Ecol Manag Restor. doi: 10.1111/emr.12271.

Lester, S.E., Halpern, B.S., Grorud-Colvert, K., Lubchenco, J., Ruttenberg, B.I., Gaines, S.D., et al., 2009. Biological effects within no-take marine reserves: a global synthesis. Mar Ecol Prog Ser. 384: 33-46.

Leverington, F., Costa, K.L., Pavese, H., Lisle, A., Hockings, M., 2010. A global analysis of protected area management effectiveness. Environ manage. 46(5): 685-698.

Lubchenco, J., Grorud-Colvert, K., 2015. Making waves: The science and politics of ocean protection. Science. 350(6259): 382-3.

Lubchenco, J., Palumbi, S.R., Gaines, S.D., Andelman, S., 2003. Plugging a hole in the ocean: the emerging science of marine reserves. Ecol Appl. 13, 3e7.

McClanahan, T.R., Marnane, M.J., Cinner, J.E., Kiene, W.E., 2006. A comparison of marine protected areas and alternative approaches to coral-reef management. Curr. Biol. 16: 14081413. 
623

624

625

626

627

628

629

630

631

632

633

634

635

636

637

638

639

640

641

642

643

644

645

646

647

648

649

650

651
Micheli, F., Halpern, B.S., Botsford, L.W., Warner, R.R., 2004. Trajectories and correlates of community change in no-take marine reserves. Ecol Appl. 14(6): 1709-23.

Nanus, B., 1992. Visionary Leadership: Creating a Compelling Sense of Direction for Your Organization: ERIC.

Parma, A.M., 1998. What can adaptive management do for our fish, forests, food, and biodiversity? Integr Biol. Published in Association with The Society for Integrative and Comparative Biology. 1(1): 16-26.

Pelletier D., García-Charton J.A., Ferraris J., David G. et al. 2005 Designing indicators for assessing the effects of marine protected areas on coral reef ecosystems: A multidisciplinary standpoint. Aquat Living Resour. 18: 15-33.

Pendleton L. H., Ahmadia G. N., Browman H. I., Thurstan R. H., Kaplan D. M. and Bartolino V. 2017. Debating the effectiveness of marine protected areas. ICES Journal of Marine Science. doi:10.1093/icesjms/fsx154.

Pomeroy, R.S., Parks, J.E., Watson, L.M., 2004. How is your MPA doing?: a guidebook of natural and social indicators for evaluating marine protected area management effectiveness: IUCN.

Rodríguez-Rodríguez, D., Rodríguez, J., Malak, D.A., 2016. Development and testing of a new framework for rapidly assessing legal and managerial protection afforded by marine protected areas: Mediterranean Sea case study. J. Environ. Manage. 167: 29-37.

Sala, E., Costello, C., Dougherty, D., Heal, G., Kelleher, K., Murray, J.H., et al., 2013. A general business model for marine reserves. PLoS One. 8(4), e58799. 
652

653

654

655

656

657

658

659

660

661

662

663

664

665

666

667

668

669

670

671

672

673

674

675

676

677

678

679

680

681

Sala, E., Giakoumi, S., 2017. No-take marine reserves are the most effective protected areas in the ocean. Ices J Mar Sci. doi:10.1093/icesjms/fsx059

Sandin, S.A., Sala, E., 2012. Using successional theory to measure marine ecosystem health. Evol Ecol. 26(2): 435-48.

Sandin, S.A., Smith, J.E., DeMartini, E.E., Dinsdale, E.A., Donner, S.D., Friedlander, A.M., et al., 2008. Baselines and degradation of coral reefs in the northern Line Islands. PLoS one. 3(2): e1548.

Scianna, C., Niccolini, F., Bianchi, C.N., Guidetti, P., 2018. Applying organization science to assess the management performance of Marine Protected Areas: An exploratory study. J. Environ. Manage. 223: 175-184.

Scianna, C., Niccolini, F., Gaines, S.D., Guidetti, P., 2015. 'Organization Science': a new prospective to assess marine protected areas effectiveness. Ocean. Coast. Manage. 116: 443448.

Stolton, S., Hockings, M., Dudley, N., MacKinnon, K., Whitten, T., Leverington, F., 2007. Management effectiveness tracking tool: reporting progress at protected area sites. World Bank/WWF Alliance by WWF International, Gland.

UNEP., 2015. Transforming our world: the 2030 Agenda for Sustainable Development. $\mathrm{A} / \mathrm{RES} / 70 / 1$.

UNEP-WCMC, IUCN, 2016. Update on global statistics December 2016. Cambridge, UK and Gland, Switzerland.

Watson, J.E., Dudley, N., Segan, D.B., Hockings, M., 2014. The performance and potential of protected areas. Nature. 515: 67-73. 
Worm, B., 2017. Marine conservation: How to heal an ocean. Nature. 543: 630-631.

683

684

Worm, B., Hilborn, R., Baum, J., Branch, T.A., Collie, J.S., Costello, C., et al., 2009. 685

686

Rebuilding global fisheries. Science. 325: 578-584.

687 
688

689

690

691

692

693

694

695

696

697

698

699

700

701

702

703

704

705

706

707

708

709

710

711 - "marine protected area*" and Bergeggi,

712 - "natural reserve*" and Bonifacio,

713 - "marine reserve*" and Cala Ratjada,

714 - "marine park*" and "Côte Bleue",

715 - "marine protected area*" and Portofino,

716 - "marine protected area*" and Porto Cesareo, 
- "marine protected area*" and Tavolara,

718 - "marine protected area*" and "Torre Guaceto",

719 - "marine protected area*” and Tremiti,

720 - "marine protected area*" and Ustica,

721 - "marine park"” and Zakynthos.

722 We also searched for papers that: 1) measured at least one of the four key ecological variables (fish density, fish

723 biomass, individual fish size, fish species richness), 2) considered the whole fish assemblages, 3) reported a

724 measure of variance from the mean (standard deviation or error) for the measured variable(s), 4) collected data in

725 the fully protected (i.e. no-take) area of the MPA and in adjacent unprotected areas outside the MPA, or in the

726 fully protected area and in the partially protected area in the case of MPAs that do not have unprotected areas in

727 proximity (e.g. islands whose coastal waters are entirely embedded within the MPA). We set a temporal frame

728 (01/01/2012 to 27/05/2016) relevant to the period to which the organizational data of the investigated MPAs refer

729 (2014).

730

731 Table SM.1 - List of unpublished technical reports from which ecological data were

732 extracted

\begin{tabular}{|c|c|c|c|}
\hline MPA & Title & Year & Author \\
\hline Bergeggi & $\begin{array}{l}\text { Valutazione della fauna ittica costiera e monitoraggio dell'effetto } \\
\text { riserva presso l'Area Marina Protetta 'Isola di Bergeggi' }\end{array}$ & 2014 & Guidetti et al. \\
\hline Côte Bleue & $\begin{array}{l}\text { Suivi des peuplements de poissons de la Réserve Marine du Cap } \\
\text { Couronne (Parc Marin de la Côte Bleue) }\end{array}$ & 2015 & Le Diréach et al. \\
\hline Portofino & $\begin{array}{l}\text { Monitoraggio dell'effetto riserva presso l'Area Marina Protetta di } \\
\text { Portofino }\end{array}$ & 2014 & Guidetti et al. \\
\hline Tavolara & $\begin{array}{l}\text { Relazione tra 'effetto riserva' e piccola pesca nell'ottica della } \\
\text { sostenibilità all'interno dell'Area Marina Protetta 'Tavolara-Punta } \\
\text { Coda Cavallo' }\end{array}$ & 2015 & Guidetti et al. \\
\hline Torre Guaceto & $\begin{array}{l}\text { Monitoraggio delle specie ittiche e delle attività di piccola pesca ai } \\
\text { fini della contabilità ambientale }\end{array}$ & 2015 & Guidetti et al. \\
\hline Tremiti & $\begin{array}{l}\text { Monitoraggio della fauna ittica presso l'AMP Isole Tremiti ai fini } \\
\text { della valutazione degli effetti della protezione/gestione e } \\
\text { regolamentazione della pesca }\end{array}$ & 2013 & Guidetti et al. \\
\hline Zakynthos & $\begin{array}{l}\text { Management Measures for Fisheries in the Marine Protected Area } \\
\text { of the National Marine Park of Zakynthos }\end{array}$ & 2013 & Dimitriadis et al. \\
\hline
\end{tabular}


From each report, we extracted data from text, tables, and figures for the four ecological variables inside the fully protected area of the MPA (Marine Protected Area) and in unprotected areas outside the MPA borders. Just for Tremiti MPA we extracted the data from the fully protected and the partially protected areas (in the latter both commercial and recreational fishing are authorized), as this MPA is a small archipelago and does not have an open access area in proximity. To extract data from figures we used the free software WebPlotDigitizer (https://automeris.io/WebPlotDigitizer/). We focused on fish data from rocky habitats, since the majority of monitoring was done in this habitat. When reports provided data through time, we averaged them in order to rely on a larger number of replicates and approximate average condition in time.

Table SM.2 - Correlation coefficient among the predictor organizational, design and implementation features

Correlation coefficients (cc) and $\mathrm{p}$ values of the correlations among the five organizational, design and implementation features. Size= organizational size, ratio between FTE (full-time equivalent employees) and the total surface area. MPI= Management Performance Index. Tot surface $=$ total surface area in hectares. No-take surface $=$ fully protected surface area in hectares. Age $=$ the number of years between the implementation of the MPAs and 2014, the year of collection of the majority of the ecological data and the organizational data.

\begin{tabular}{|l|l|l|l|l|}
\hline Size & $\begin{array}{l}\mathrm{cc}=-0.48 \\
p \text {-value }=0.23\end{array}$ & & & \\
\hline MPI & $\mathrm{cc}=0.19$ & $\mathrm{cc}=0.19$ & & \\
& $p$-value $=0.65$ & $p$-value $=0.65$ & & \\
\hline Tot surface & $\mathrm{cc}=0.02$ & $\mathrm{cc}=-0.43$ & $\mathrm{cc}=-0.16$ & \\
& $p$-value $=0.96$ & $p$-value $=0.29$ & $p$-value $=0.70$ & \\
\hline No-take surface & $\mathrm{cc}=0.03$ & $\mathrm{cc}=-0.62$ & $\mathrm{cc}=-0.21$ & $\mathrm{cc}=0.83$ \\
& $p$-value $=0.95$ & $p$-value $=0.11$ & $p$-value $=0.61$ & $p$-value $=0.01$ \\
\hline & Age & Size & MPI & Tot surface \\
\hline
\end{tabular}


Table SM.3 - Relationships between fish biomass log-response ratio and organizational, design and implementation features

Relationships between fish biomass log-response ratio and organizational, design and implementation features for the eight studied Marine Protected Areas based on DISTLM (distance-based multivariate analysis for a linear model) for marginal test (a) and conditional test (b).

\begin{tabular}{cccccc}
\hline $\begin{array}{c}\text { Organizational, design and } \\
\text { implementation features }\end{array}$ & SS & Pseudo-F & $P$ & $\begin{array}{c}\text { Proportion of } \\
\text { explained variability }\end{array}$ & $\begin{array}{c}\text { Cumulative total of } \\
\text { explained variability }\end{array}$ \\
\hline
\end{tabular}

(a) Marginal test

$\begin{array}{lllll}\text { MPI } & 1.13 & 10.09 & 0.02 & 0.63 \\ \text { Organizational size } & 0.77 & 4.36 & 0.08 & 0.42 \\ \text { Total surface area } & 0.18 & 0.35 & 0.58 & 0.05 \\ \text { Age } & 0.18 & 0.67 & 0.45 & 0.10\end{array}$

(b) Conditional test

\begin{tabular}{lccccc} 
MPI & 1.13 & 10.09 & 0.02 & 0.63 & 0.63 \\
Organizational size & 0.47 & 11.30 & 0.03 & 0.26 & 0.88 \\
Age & 0.10 & 4.11 & 0.09 & 0.06 & 0.94 \\
\hline
\end{tabular}

759 
761 Table SM.4 - Relationships between fish biomass log-response ratio and CGI (culture

762 and goal index) and SI (strategy index)

Relationships between fish biomass log-response ratio and CGI (culture and goal index) and SI (strategy index) for the eight Marine Protected Areas based on DISTLM (distance-based multivariate analysis for a linear model) 765 for marginal test (a) and conditional test (b).

766

Organizational features

SS

Pseudo-F

Proportion of

Cumulative total of

explained variability explained variability

(a) Marginal test

SI

15.25

5.69

0.01

0.49

CGI

19.84

10.38

0.00

0.63

(b) Conditional test

$\begin{array}{lllllr}\text { SI } & 19.84 & 10.38 & 0.00 & 0.63 & 0.63 \\ \text { CGI } & 10.90 & 96.48 & 0.00 & 0.35 & 0.98\end{array}$

767

768 
Table SM.5 - Relationships between fish biomass log-response ratio and SI subcomponents

771 Relationships between fish biomass log-response ratio and EEI (environmental education index), EI (enforcement 772 index), MI (monitoring index) and MDI (management data index), for the eight Marine Protected Areas based on DISTLM (distance-based multivariate analysis for a linear model procedure) for a) marginal test and b) conditional test.

775

\begin{tabular}{llllrl}
\hline $\begin{array}{l}\text { Organizational } \\
\text { features }\end{array}$ & SS & Pseudo-F & $P$ & $\begin{array}{l}\text { Proportion } \\
\text { explained variability }\end{array}$ & $\begin{array}{l}\text { Cumulative total of } \\
\text { explained variability }\end{array}$ \\
\hline
\end{tabular}

(a) Marginal test

$\begin{array}{lllll}\text { EEI } & 6.30 \times 10^{6} & 2.09 \times 10^{5} & 0.99 & 3.48 \times 10^{6} \\ \text { EI } & 0.14 & 0.49 & 0.51 & 0.07 \\ \text { MI } & 0.13 & 0.45 & 0.52 & 0.07 \\ \text { MDI } & 0.23 & 0.86 & 0.38 & 0.12\end{array}$

(b) Conditional test

$\begin{array}{llllll}\text { MDI } & 0.23 & 0.86 & 0.39 & 0.12 & 0.12 \\ \text { EEI } & 0.54 & 2.61 & 0.18 & 0.30 & 0.42\end{array}$


Table SM.6 - Relationships between fish biomass log-response ratio and Management

Relationships between fish biomass log-response ratio and MPI= Management Performance Index, total number of employees, total surface area and age for the 8 Marine Protected Areas, based on DISTLM (distance-based

\begin{tabular}{|c|c|c|c|c|c|}
\hline $\begin{array}{l}\text { Organizational, design and } \\
\text { implementation features }\end{array}$ & SS & $\begin{array}{l}\text { Pseudo- } \\
\text { F }\end{array}$ & & $\begin{array}{l}\text { Proportion of } \\
\text { explained variability }\end{array}$ & $\begin{array}{l}\text { Cumulative total } \\
\text { explained variability }\end{array}$ \\
\hline
\end{tabular}

(a) Marginal test

$\begin{array}{lllll}\text { MPI } & 1.13 & 10.09 & 0.02 & 0.63 \\ \text { Total number of employees } & 0.02 & 0.07 & 0.78 & 0.01 \\ \text { Total surface area } & 0.10 & 0.35 & 0.59 & 0.05 \\ \text { Age } & 0.18 & 0.67 & 0.45 & 0.10\end{array}$

(b) Conditional test

$\begin{array}{llllll}\text { MPI } & 1.13 & 10.09 & 0.02 & 0.63 & 0.63 \\ \text { Age } & 0.41 & 7.62 & 0.05 & 0.22 & 0.85 \\ \text { Total number of employees } & 0.08 & 1.72 & 0.26 & 0.04 & 0.90\end{array}$

784 